to reason about" by virtue of the identity $(x+7+10)(1,000-8) / 992-7=x$.

Carroll wrote to newspapers. On 8 April 1856, Jelinger Symons, Her Majesty's Inspector of Schools, wrote to The Times to point out that the Moon did not rotate on its axis. (His reason: it presents the same face to the Earth all the time.) Carroll wrote a reply, but it was not among the seven published. Symons persisted; the correspondence continued for a month before petering out. Bizarrely, when the same question was raised ten years later in the United States, the letters column of Scientific American debated the issue for three years.

Carroll was a master of deception, leaving innumerable time bombs for later scholars to explode or defuse. A famous letter to Maggie Cunnynghame ends with a postscript: "My love to yourself - to your Mother my kindest regards - to your small, fat, impertinent, ignorant brother, my hatred. I think that is all." Although often quoted as prose, it is actually in verse. The lines terminate at 'Mother', 'small', 'brother', 'all'; the metre is perfect. His acrostic dedications are famous. The prefatory poem to Alice in Wonderland uses the word 'little' three times: this is a pun on the three Liddell sisters, one of whom was the real-life Alice.

Carroll couldn't resist puns, good or bad. "How does a doll know that a hand which came off was her right hand?" "Because the other was left." Enjoy.

Ian Stewart is in the Department of Mathematics, University of Warwick, Coventry CV4 TAL, UK.

Also of interest
The Red King's Dream: or Lewis Carroll in
Wonderland by Jo Elwyn Jones and
Francis Gladstone. In a personal quest,
prompted by a link between Carroll and
their forebear, the Victorian Prime Minister
William Gladstone, the authors have
revisited Carroll's diaries and haunts,
rediscovering little-known information.
They have unravelled the code that Carroll
used to secrete into his Alice stories his
scurrilous views on various figures of
Victorian England. Pimlico, $£ 10$.

\section{Looking after your invention}

Robert I. James

Technology Transfer: Making the Most of Your Intellectual Property. By Neil F. Sullivan. Cambridge University Press: 1995. Pp. 221. £40, \$69.95 (hbk); $£ 14.95, \$ 24.95$ (pbk).

TRANSFERRING technology from academic institutions to industry, especially in the life sciences, is a process that is stimulating much debate. In the United Kingdom, for example, conferences are being held to consider various aspects of technology transfer, the government is setting up initiatives to encourage innovation, universities are building up their technology transfer offices and the Charity Commission is considering how research charities should approach the whole business of commercializing the fruits of their research portfolios.

There are several reasons for this heightened interest. First, transferring technology to a commercial entity (whether a start-up company or an established pharmaceutical company) is the only way for an invention to be developed with a view ultimately to selling the product. In academic medical research directed at discovering new therapies for treating disease, effective technology transfer is therefore the only way that patients worldwide will benefit from new discoveries. Second, successful technology transfer can generate considerable long-term revenues for the inventors, host institutions and funding bodies. Third, start-up companies based on new technology create jobs and have the potential to bring enormous economic benefits to regions where they are sited.

So this book arrives at just the right time. Aimed mainly at academic researchers in the life sciences, it sets out to discuss all the issues they need to consider to commercialize technology successfully, from deciding whether they have something of value to 'creating a culture' in a new company.

Perhaps the most sophisticated approach to technology transfer in the life sciences is to create a company to exploit a particular piece of technology. Over a period of several years, such companies can bring large returns to their founders as they float on stock markets around the world or form alliances with large pharmaceutical companies. Barely a week goes by without details of new ventures, new rounds of financing or new deals being reported in publications such as Scrip, the international pharmaceutical newsletter. But to the author's credit, his book does not just deal with the 'glamorous' subjects but recognizes that technology transfer is an activity that offers a number of possible ways to exploit intellectual property depending on the nature of the technology. Setting up a new company is clearly one of these choices, but other mechanisms are also considered, such as setting up consultancies, contract research arrangements and collaborative research agreements.

When an academic inventor has made an invention, its potential commercial value will be fundamentally affected by whether or not it is patentable. Patentability is mainly determined by the answer to three questions. Is the invention novel? Did its creation involve an inventive step? Does it have industrial utility? In the first instance, the inventor and his or her advisers will form a view on patentability, but ultimately the issue will be decided by examination of the patent application in the various regional and national patent offices and possibly, if the patent is challenged, in a court of law. The book deals in some detail with the various processes involved in filing and prosecuting a patent application. In addition, it includes a useful section, for scientists working outside the United States, on the importance of maintaining proper notebooks following changes brought about by the General Agreement on Tariffs and Trade Implementation Act in the United States.

As is clear from the later chapters of the book, filing the patent application is only the start of the commercialization process. For the patent application to be a valuable asset rather than an expensive administrative burden, careful consideration must be given to its value and the best way to exploit it. When the commercial strategy has been decided, it needs to be implemented by identifying partners, negotiating agreements, or, if a new company is to be established, attracting investors, and so on. The practicalities surrounding the commercialization of an invention are discussed, with references to further sources of information.

But in dealing with a very wide range of subjects and attempting to describe the various processes in minute detail, the book dilutes the fundamental principles of patenting, valuing and commercializing technology in the life sciences. Nevertheless, at a time when technology transfer is becoming more and more important, any book that tries to pull together a practical overview of the field should be welcomed.

Robert I. James is at Cancer Research Campaign Technology Ltd, 6-10 Cambridge Terrace, Regent's Park, London NW1 4JL, UK.

\section{New in paperback}

The Common But Less Frequent Loon and Other Essays by Keith Stewart Thomson. Yale University Press, $\mathbf{1 1 0 . 9 5 .}$ Essays from the author's "Marginalia" column in American Scientist. "Try these essays for bedtime: you can't go far wrong", Michael Taylor, Nature 368, 362 (1994).

NATURE · VOL 381 · 27 JUNE 1996 